\title{
THE EFFECTS OF MALPRACTICE PRESSURE AND LIABILITY REFORMS ON PHYSICIANS' PERCEPTIONS OF MEDICAL CARE
}

\author{
DANIELP. KESSLER *AND MARK B. MCCLELLAN ${ }^{* *}$
}

\section{INTRODUCTION}

The medical malpractice liability system has two main purposes. ${ }^{1}$ First, it seeks to provide compensation to patients who suffer negligent medical injury, thereby acting as a source of insurance. ${ }^{2}$ Second, it seeks to penalize physicians whose negligence causes patient injury, thereby providing the incentives to take appropriate precautions in medical treatment. ${ }^{3}$

H owever, considerable evidence suggests that the current system accomplishes neither of these objectives. R egarding the first, the tort system does not provide compensation rapidly or equitably to injured patients. Justice for medical malpractice claimants is subject to lengthy delays: O $n$ average, it takes four to five years to resolve a malpractice claim. ${ }^{4}$ In addition, while one in fifteen patients who suffer an injury due to medical negligence receive compensation, only one-sixth of the cases that receive compensation have positive evidence of negligent medical injury. ${ }^{5}$

The performance of the liability system in terms of the second objective de-

Copyright @ 1997 by L aw and Contemporary Problems

* A ssistant Professor of Economics, Law, and Policy, Graduate School of B usiness, Stanford U niversity; F aculty R esearch Fellow, N ational B ureau of E conomic R esearch ("NBER").

** A ssistant Professor of E conomics and A ssistant Professor of M edicine, Stanford U niversity; Faculty R esearch Fellow, NBER.

We gratefully acknowledge Patricia Born, David E mmons, M artin H atlie, James R odgers, James Todd, and the A MA for making the Socioeconomic Monitoring System Survey data available to us. We appreciate the A gency for Health Care Policy and R esearch, the National Science Foundation, and the National Institutes on A ging for providing research support through the NBER, and the J ohn M. O lin Foundation for fellowship support. In addition, we would like to thank Thomas M etzloff, Frank Sloan, and Sara Thran for helpful comments. A Il errors, however, are our own.

1. See, e.g., Patricia M. Danzon, Medical Malpractice: Theory, Evidence And PUBLIC POLICY 3 (1985).

2. Seeid.

3. Seeid.

4. See Frank A. Sloan et al., Suing for Medical Malpractice 26 tbl.2.4 (1993). The referenced time period for claim resolution is from incident to disposition. See id.

5. See Paul C. Weiler et al., a Measure of Malpractice: Malpractice litigation A nd Patient Compensation 139 (1993); HaRVard Medical Practice Study, Patients, DOCTORS, LAWYERS: MEDICA L INJURY, MA LPRA CTICE LITIGATION, AND PATIENT COMPENSATION IN NEW Y ORK, exec. summary 6 (1990). 
pends on the extent to which the system induces physicians to take socially appropriate precautions against medical injuries. Because precautionary medical care is costly, it is not in society's interest as a whole to establish a malpractice system that requires physicians to utilize every available medical technology in the treatment of every patient for whom that technology offers even the slimmest of health benefits. ${ }^{6}$ Instead, as first outlined by L earned $\mathrm{H}$ and in U.S. vs. Carroll Towing, the socially optimal level of precaution against accidental injury will be obtained when the liability system punishes defendants that take less care than that level at which the marginal social benefits from additional precaution, in terms of improved patient health, are exactly equal to the marginal social costs.

In theory, the existing medical malpractice liability system may or may not provide physicians with the incentives to take the optimal level of precautions. On one hand, malpractice penalties optimally may deter physicians and other health care providers from putting patients at excessive risk of adverse health outcomes. The malpractice system may affect physician behavior even though virtually all physicians are insured against the financial consequences of malpractice in the form of legal damages; ${ }^{8}$ physicians may be motivated to take care to avoid nonfinancial penalties of malpractice claims such as reputational harm and the time and unpleasantness of defending a claim. ${ }^{9}$ To the extent that managed care encourages physicians to reduce treatment intensity, the malpractice system may be an important counterweight for preserving patient access to necessary care. ${ }^{10}$

On the other hand, these penalties may drive physicians to be "too careful"-to practice defensive medicine. Because of third-party payers, such as patients' health care plans and insurance, neither patients nor physicians bear a substantial share of the costs of medical care associated with precaution in any particular case. A ccordingly, very small increases in the expected "hassle" from a malpractice claim or lawsuit may result in large increases in medical treatment intensity that, at the margin, generate only minimal health benefits. ${ }^{11}$

6. See DANZON, supra note 1, at 10; see also id. at 120-24 (discussing optimal levels of prevention).

7. 159 F.2d 169, 173 (1947).

8. See, e.g., A nn G. Lawthers et al., Physician Perceptions of the Risk of Being Sued, 17 J. HEA LTH POL., POL'Y \& L . 463, 476 (1992); Frank A. Sloan, Experience R ating: D oes It M ake Sense for M edical M alpractice Insurance?, 80 A M. E CON. R EV . 128 (1990).

9. See, e.g., WEILER ET AL., supra note 5, at 18; U.S. CONGRESS, OfFICE OF TECHNOLOGY A SSE SSMENT, I M PA CT OF LEGAL REFORMS ON MEDICA L M ALPRA CTICE COSTS 7 (1993) [hereinafter OTA ].

10. See Daniel P. Kessler \& Mark B. McClellan, Moral Hazard, Managed Care, and Defensive $M$ edicine (unpublished manuscript, on file with authors).

11. Socially excessive precaution and defensive medicine can take many forms. When physicians avoid high-risk patients or procedures to the detriment of patient health, they are practicing negative defensive medicine. When physicians engage in precautionary treatment with minimal expected medical benefit relative to the cost of the treatment, they are practicing positive defensive medicine. Hereinafter, we use the generic term "defensive medicine" to refer exclusively to positive defensive medicine. See David K lingman et al., M easuring D efensive M edicine U sing Clinical Scenario Surveys, 21 J. HEALTH POL., POL'Y \& L. 185, 189 (1996). 
In previous research, we found that the existing liability system provides physicians with incentives to practice defensive medicine. ${ }^{12}$ We tested for the existence and assessed the magnitude of defensive treatment behavior by calculating the cost of an additional year of life or an additional year of cardiac health achieved through malpractice-pressure-induced treatment intensity. ${ }^{13}$ If liability-induced precaution were resulting in low expenditures per year of life saved relative to generally accepted costs per year of life saved of other medical treatments, then the existing liability system would be providing incentives for efficient care; but if liability-induced precaution were resulting in high expenditures per year of life saved, then the liability system would be providing incentives for socially excessive care. ${ }^{14}$ B ecause we found that reductions in medical malpractice tort liability lead to reductions in the intensity of medical treatment but not to increases in adverse health outcomes, we concluded that medical care for cardiac illness is defensive. ${ }^{15}$

The social costs of defensive medicine are likely to be large, indeed far larger than the "direct" social costs of the liability system. The direct total costs of the system (for example, the costs of compensating claimants and plaintiffs, the time of the parties, attorneys' and experts' fees, salaries of judges, and other court costs) are less than one percent of all health care expenditures. ${ }^{16}$ Furthermore, because compensation paid to claimants and plaintiffs is a transfer rather than a real consumption of resources, the true direct social costs of the system are even smaller. The indirect costs of the system-those attributable to defensive treatment-are estimated to be much greater. For example, our previous research estimates the share of medical expenditures on hospital services for elderly patients with cardiac illness attributable to defensive practices to be approximately five to nine percent. ${ }^{17}$ Broader analyses suggest that the share of aggregate medical expenditures spent on defensive behavior may be even greater. ${ }^{18}$

For these reasons, further research into the causes of defensive medicine can guide reforms of the medical malpractice liability system. To do so, such

12. See Daniel P. Kessler \& M ark B. M cClellan, D o D octors Practice D efensive M edicine?, 111 Q.J. E CON. 353, 388 (1996). In that study, we used longitudinal data on all elderly M edicare recipients hospitalized for treatment of cardiac illness in 1984, 1987, and 1990, matched with information on tort laws and law reforms from the state in which the patient was treated. See id. at 354. We studied the effect of liability-reducing law reforms on total hospital expenditures on the patient in the year after the initial hospitalization to measure intensity of treatment; we also modeled the effect of law reforms on several important patient health outcomes. See id. at 361-66. We compared trends in expenditures and outcomes for patients from states adopting liability-reducing tort reforms to those for patients from states that did not adopt tort reforms. See id. at 372-87.

13. See id. at 378-79.

14. See id. at 355 .

15. See id. at 388.

16. See OTA, supra note 9 , at 5 .

17. See K essler \& M cClellan, supra note 12 , at 383.

18. See, e.g., Roger A. R eynolds et al., The Cost of Medical Professional Liability, 257 J A M A 2776, 2781 (1987); see also J ames W. M oser \& R obert A . M usacchio, The Cost of M edical Professional L iability in the 1980s, 7 J. MED. PRA C. M G M T. 6, 7-9 (1991)(discussing the findings of Roger R eynolds, supra). 
research needs to focus on the relationships between liability laws, malpractice pressure, physician perceptions, medical treatment decisions, medical costs, and health outcomes in order to investigate how and why doctors practice defensive medicine. To investigate how doctors practice defensive medicine, we estimated separately the impact of liability reforms on diagnostic and therapeutic medical expenditures. ${ }^{19}$ To investigate why doctors practice defensive medicine, we identified the effect of liability reforms on outcomes of the legal system and physician incentives to practice defensively, and the extent to which law-induced changes in different types of incentives actually affect medical costs and patient health outcomes. ${ }^{20}$ In another research project, we modeled the role of physician and hospital moral hazard due to health insurance, ${ }^{21}$ and we estimated the impact of managed care and the interaction between managed care and liability reform on treatment decisions, health care costs, and health outcomes. ${ }^{22}$

In this paper, we use repeated cross-sections of the A merican M edical A ssociation Socioeconomic Monitoring System ("A MA SM S") survey that reported physicians' experiences from 1984 through $1993,{ }^{23}$ matched with data on state liability reforms, to examine the relationship between liability reforms, malpractice pressure, and physician perceptions of medical care. We estimate the impact of reforms on trends over time both in measures of malpractice pressure (such as malpractice claims rates and malpractice insurance premiums) and in physician perceptions of the importance of malpractice-pressureinduced changes in practice patterns.

In addition, we seek to validate physicians' reported perceptions as a meas-

19. Daniel P. Kessler \& Mark B. McClellan, How Liability Law A ffects Medical Productivity (unpublished manuscript, on file with authors). Preliminary results from this study suggest that liability reforms reduce the prevalence of defensive medicine by reducing both financial and nonfinancial dimensions of malpractice pressure. See id. States adopting "direct" reforms, see infra Part III.A ., showed lower trend growth in each measure of malpractice pressure that we studied-the frequency of malpractice claims, the likelihood of delay in claim resolution, the likelihood of high settlement amounts, and the likelihood of costly litigation-relative to nonadopting states. R eform-induced reductions in each dimension of malpractice pressure reduced growth in medical treatment intensity for elderly patients with cardiac illness, but did not systematically lead to increases in trends in adverse health outcomes. See id.

20. See id.

21. For a discussion of physician and hospital moral hazard due to health insurance, see CLARK C. havighurst, health Care Cholces: Private Contracts as Instruments of health REFORM 13-15 (1995).

22. See Kessler \& M CClellan, supra note 10.

23. Center for health Policy Research, ama, Socioeconomic Characteristics of MEDICA L PRA CTICE 1994 app. A at 163 (M artin L. Gonzalez ed., 1994). The A M A SM S surveys provide representative information on the population of all nonfederal physicians, excluding residents, who spend the greatest proportion of their time in patient care activities. Samples of the SM S are selected from the A M A Physician M asterfile, which contains current and historical information on every M.D. in the U nited States. See id. The A M A SM S core questionnaire includes questions on practice characteristics, hours and numbers of patient visits, fees, income and expenses, third-party payors and their characteristics, and specialty-specific fees and procedures. See id. at 164, app. C at 172-75. In addition, the AMA SMS includes periodic supplemental surveys to provide information on special topics such as malpractice. Properties of the A M A SM S are discussed below, see infra Part II.B. For more detailed information about the SMS, see AMA, SOCIOECONOMIC CHARACTERISTICS OF MEDICAL PRA CTICE (1984-1994). 
ure of actual changes in practices by estimating the joint impact of liability reforms and individual physician malpractice claims history on physician perceptions. Evidence that state-level reforms both reduce measures of malpractice pressure and reduce physician perceptions of the impact of malpractice pressure would suggest that survey methods provide valid measures of defensive practices. On the other hand, if physicians' perceptions depend only on their individual experiences and not on exogenous variation in malpractice pressure due to law reforms, then physician surveys may primarily be capturing negative feelings about the malpractice system or other unmodeled differences across physicians, rather than the impact of malpractice pressure on perceptions and practices.

The paper proceeds in four parts. Part II discusses the problem of measuring defensive medicine, sets out our research approach, and examines the role of physician surveys. Part III presents our models and outlines our analysis of the A M A SM S survey. Part IV presents our empirical results, and Part V presents our conclusions.

Measuring Defensive Medicine and PhysiCian Perceptions of the IMPACT OF THE MALPRA CTICE SY STEM ON MEDICAL CARE

Figure 1 outlines our schematic of the process by which the tort system affects medical care. Statutes and judicial decisions- the rules of the tort system-are at the base of the process. Tort law affects outcomes of the legal system such as the frequency of claims, the amount of time and physician effort needed to resolve a claim, and the size of the award. We use the term "malpractice pressure" to describe the extent to which a state's legal environment provides high benefits to plaintiffs or high costs to physicians, or both. $M$ alpractice pressure may be multidimensional and include both financial and nonfinancial factors. M alpractice pressure may affect physician perceptions of appropriate practices. Changes in perceived best practices may then translate into changes in actual treatment decisions. Finally, changes in treatment decisions may translate into changes in medical costs and possibly patient health. 
FIGURE 1

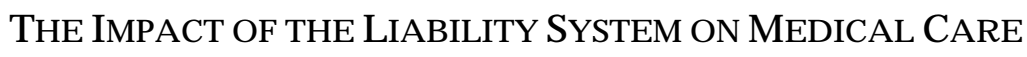

Medical Liability L aws

H ow do liability laws affect "malpractice pressure" financial and nonfinancial outcomes of the legal system?

M alpractice $A$ wards and

Litigation

How does malpractice pressure affect physician perceptions of appropriate medical practices?

Physician Perceptions of

B est Practices

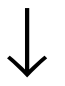

H ow do malpractice-pressure-induced changes in perceptions affect treatment decisions and medical costs?

Treatment D ecisions,

M edical Costs

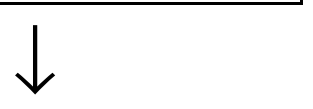

Do treatment decisions made to avoid legal liability have an effect on health outcomes?

Patient $\mathrm{H}$ ealth

O utcomes 
Physician surveys focus on the second link in the chain-the effect of malpractice pressure on physician perceptions of appropriate practices. Surveys generally take one of two forms: "direct" and "clinical scenario" surveys. D irect surveys generally ask doctors how the incentives provided by the malpractice system affect their practices. The AMA SM S survey, for example, asks, "What percentage of the diagnostic tests and treatment procedures ordered were due to concerns about malpractice?" ${ }^{24}$ Clinical scenario surveys, on the other hand, posit hypothetical clinical situations and ask physicians what they would do and why, sometimes providing a list of potential behavioral explanations including "malpractice concerns." ${ }^{25}$ D irect surveys find that physicians report substantial changes in practice patterns as a result of malpractice pressure, changes that could account for as much as fifteen percent of spending on physician services. ${ }^{26}$ Clinical scenario surveys also find that defensive medicine exists, although not to the extent suggested by the direct physician surveys. ${ }^{27}$

Surveys offer both fundamental strengths and weaknesses relative to other methods of measuring the prevalence of defensive medicine. The fundamental strength of surveys is that they focus on physicians' perceptions of the impact of the malpractice system, which may be important determinants of medical practice. The fundamental weakness of surveys is that they cannot assess whether physicians' behavioral responses to liability pressure are socially optimal or socially wasteful. Surveys may calibrate the social costs imposed by the liability system, but because they do not assess the impact of liability-induced treatment on patient health, they cannot measure the social benefits that the system may create.

In addition to this fundamental weakness, the existing survey literature has other shortcomings stemming from its relatively narrow focus on the relationship between malpractice pressure and physician perceptions. ${ }^{28}$ First and foremost, surveys are prone to response bias. This problem may be particularly acute in direct physician surveys, in which physicians may be tempted to exaggerate the impact of malpractice pressure in order to buttress a political argument in favor of liability reform. ${ }^{29}$ Indeed, physicians estimate the probability of defending against a malpractice claim in any one year at about three times the actual probability of such a claim arising. ${ }^{30}$ Clinical scenario surveys may avoid some of these problems, but the specification of a list of explanations for

24. AMA SM S, 1993 Core Survey Codebook.

25. K lingman et al., supra note 11, at 193-94.

26. See, e.g., Sara C. Charles et al., Physicians on Trial-Self-Reported Reactions to Malpractice Trials, 148 W.J. MED. 358, 358-60 (1988); A nn G. Lawthers et al., supra note 8, at 478; Moser \& M usacchio, supra note 18, at 7-9; R eynolds et al., supra note 18, at 2776; M argo L. R osenbach \& A shley G. Stone, M alpractice I nsurance Costs and Physician Practice, 1983-1986, 9 HEA LTH A FF. 176, 18285 (W inter 1990). A comprehensive review of these studies can be found in U.S. CONGRESS, OFFICE of TECHNOLOgy A SSESSMENT, DEFEnSIVE MEDICINE AND MEDICAL MALPRACTICE, OTA-H-602, ch. 3 (1994) [hereinafter OTA ].

27. See, e.g., OTA supra note 26 , at 56.

28. See, e.g., id.; K lingman et al., supra note 11 , at 191.

29. See K lingman et al., supra note 11 , at 191.

30. See L awthers et al., supra note 8 , at 463 . 
a treatment decision inevitably raises similar concerns. ${ }^{31}$

A second criticism is that previous studies using survey data have provided evidence only on the baseline level of treatment behavior undertaken out of liability concerns, not on the incremental response of defensive behavior to specific policy reforms. Because some treatments undertaken out of liability concerns may improve health, estimates of the total effect of malpractice liability on medical costs necessarily overstate the costs of defensive medicine. For purposes of policy evaluation, research should consider both the medical costs and the health benefits of changes in treatment behavior attributable to proposed changes in the liability system.

Third, unobserved differences in the characteristics of patients or health care providers means that reported correlations between malpractice pressure and behavioral change may be noncausal. A provider reporting high levels of malpractice pressure and high levels of liability-induced treatment may be responding to tort incentives. A Iternatively, such a provider may have adopted relatively intensive treatment patterns and have suffered from frequent claims and high insurance premiums as a result of other underlying factors, such as having patients with a high level of disease severity or unusually high expectations for medical interventions and health outcomes. In this case, the apparent association between malpractice pressure and behavioral change would not represent the causal impact of the liability system, but rather the effects of the underlying, unobserved factors affecting both legal system outcomes and physician attitudes or behavior.

D espite these concerns, no previous research has sought to expand analysis of survey data to include other aspects of the relationship between liability law and medical care. We address here the key criticisms of the survey literature by linking survey data with data on state liability reforms and with measures of malpractice pressure, such as malpractice claim rates and malpractice insurance premiums. We estimate the extent to which exogenous law reforms affect malpractice pressure and physician perceptions of defensive medicine to provide policy-relevant evidence on the marginal, causal impact of reforms. In addition, we investigate the hypothesis of response bias by estimating the joint impact of liability reforms and individual physician malpractice claims history on physician perceptions. E vidence that state-level reforms reduce both malpractice pressure and physician perceptions of the incidence of defensive medicine would suggest that survey methods provide valid measures of defensive practices. If physicians' perceptions depend only on their individual experiences and not on exogenous variation in malpractice pressure due to law reforms, then physician surveys may be capturing negative feelings about the malpractice system, or unobserved differences across physicians, rather than the impact of malpractice pressure on perceptions and practice patterns.

31. See K lingman et al., supra note 11 , at 192. 
III

MODELSAND DATA

A. Models

We developed statistical models that measure the effects of changes in medical liability laws on changes in malpractice pressure and in physician perceptions of liability-induced treatment intensity. R estated, we compare differences in time trends between states that enacted liability-reducing reforms and states that did not. A Ithough this modeling strategy neglects the vast commonality between states in their malpractice systems, and therefore cannot assess the total social costs (or social benefits) that may result from the U S. malpractice system, it offers several advantages. Most importantly, it provides policyrelevant assessments of the incremental response of defensive behavior to specific legal reforms. In addition, by basing our estimates on differences in time trends, we estimate the effects of laws while controlling for fixed differences between states and fixed differences over time. ${ }^{32}$

We observe successive cohorts of physicians over the $1984-93$ period. In state $s=1, \ldots, S$ during year $t=1, \ldots, T$, our observational units consist of individual physicians $i=1, \ldots, N_{s^{\prime}}$ E ach physician has specialty $X_{i s t^{\prime}}$ described by a set of fourteen indicator variables (there are fifteen specialty categories in our data). ${ }^{33}$ We analyze two measures of the malpractice pressure facing each physician. First, the physician may have malpractice claims filed against her in year $t$, which we denote with a claims indicator variable $C_{i s t}: C_{\text {ist }}=1$ if physician i from state $s$ had at least one malpractice claim filed against her in year $t$, and $\mathrm{C}_{\mathrm{ist}}=0$ otherwise. Second, the physician pays or has paid on her behalf annual malpractice insurance premiums $\mathrm{M}_{\text {ist' }}$ which we consistently express in the value of 1985 dollars. Physicians also report perceptions about the impact of malpractice pressure on four dimensions of their practices: record-keeping, use of diagnostic tests, referrals for consultation, and time spent with patients. We characterize these reported perceptions with four indicator variables $\mathrm{P}_{\text {ist }}{ }^{\mathrm{R}}, \mathrm{P}_{\text {ist }}{ }^{\mathrm{D}}$, $\mathrm{P}_{\text {ist }}{ }^{\mathrm{C}}$, and $\mathrm{P}_{\text {ist }}{ }^{\top}$, respectively, where $\mathrm{P}_{\text {ist }}{ }^{\mathrm{x}}=1$ if the physician reported that she changed that dimension of her treatment behavior in response to malpractice pressure, and $\mathrm{P}_{\text {ist }}{ }^{\mathrm{x}}=0$ otherwise.

Table 1 summaries the eight types of state medical malpractice liability law reforms that we analyze: caps on damage awards, abolition of punitive damages, no mandatory prejudgment interest, collateral source rule reforms (which require damages to be reduced by all or part of the dollar value of collateralsource payments to the plaintiff), caps on contingency fees, mandatory periodic payments, joint-and-several liability reform, and the existence of a patient

32. This would be important if there were fixed differences across geographic areas in attitudes toward the tort system that were correlated with laws. For a discussion of the potential importance of fixed differences in areas' legal cultures, see M arc Galanter, Real World Torts: A $n$ A ntidote to A necdote, 55 M D. L. REV. 1094, 1128-29 (1996).

33. Indicator variables are assigned the values zero or one. 
compensation fund. Consistent with our other research ${ }^{34}$ and with previous research on the impact of medical malpractice liability reform, ${ }^{35}$ we group these reforms into two categories: direct and indirect reforms. Direct reforms include changes in laws that specify statutory limits on, or reductions in, malpractice awards: caps on total or noneconomic damages, collateral-source rule reforms, abolition of punitive damages, and abolition of mandatory prejudgment interest. Indirect reforms include changes that affect awards only indirectly, such as reforms imposing mandatory periodic payments (requiring damages in certain cases to be disbursed in the form of an annuity), caps on attorneys' contingency fees, and abolition of joint-and-several liability for total or noneconomic damages, either for all claims or for claims in which defendants did not act in concert. We denote the existence of law reforms in state $s$ at time t using two indicator variables, $L_{1 s t}$ and $L_{2 s t^{*}}$ If state $s$ has adopted a direct reform at time $t, L_{1 s t}=1$, and if state $s$ has adopted an indirect reform at time $t$, $\mathrm{L}_{2 s t}=1$. The variable $\mathrm{L}_{\text {st }}=\left[\mathrm{L}_{1 \mathrm{st}} \mathrm{L}_{2 \mathrm{st}}\right]$ is thus a two-dimensional binary vector describing the existence of malpractice reforms.

34. See K essler \& M cClellan, supra note 10; K essler \& M cClellan, supra note 12 , at $360,363,370$ 72; Kessler \& McClellan, supra note 19.

35. See, e.g., Patricia M. Danzon, The frequency and Severity of Medical MalPRACTICE CLAIMS (RAND R-2870-ICJ/HCFA, 1982); PATRICIA M. DANZON, NEW EVIDENCE ON the Frequency and SeVerity of Medical MaLPRA CTICE CLA IMS, (RAND R-3410-ICJ, 1986); D rucilla $\mathrm{K}$. B arker, The $\mathrm{E}$ ffects of T ort R eform on M edical $M$ alpractice Insurance $M$ arkets: A $n$ E mpirical A nalysis, 17 J. HEA LTH POL., POL'Y \& L. 143 (1992); Frank A . Sloan et al., Effects of T ort R eforms on the Value of Closed Medical Malpractice Claims: A M icroanalysis, 14 J. HEALTH POL., POL'Y \& L. 663 (1989); S. Zuckerman et al., E ffects of T ort R eforms and O ther Factors on M edical M alpractice Insurance Premiums, 27 I N Q UIRY 167 (1990). 
TABLE 1

LEGALREFORMSUSED IN A NALYSIS

\begin{tabular}{|c|c|c|}
\hline R eform & D escription Of R eform & $\begin{array}{l}\text { Predicted I mpact } \\
\text { On L iability }\end{array}$ \\
\hline Caps O n D amage & E ither N oneconomic (Pain A nd Suffering) & \\
\hline A wards & $\begin{array}{l}\text { Or T otal Damages Payable A re Capped A t } \\
\text { A Statutorily-Specified D ollar A mount }\end{array}$ & D irect \\
\hline A bolition of & M edical $M$ alpractice $D$ efendants $A$ re $N$ ot & \\
\hline Punitive $D$ amages & $\begin{array}{l}\text { L iable For Punitive D amages U nder A ny } \\
\text { Circumstances }\end{array}$ & D irect \\
\hline No M andatory & Interest O $\mathrm{n}$ E ither N oneconomic Or T otal & \\
\hline $\begin{array}{l}\text { Prejudgment } \\
\text { Interest }\end{array}$ & $\begin{array}{l}\text { D amages } A \text { ccruing From } E \text { ither The } D \text { ate } \\
\text { Of The I njury Or The D ate O f Filing Of } \\
\text { The L awsuit Is N ot } M \text { andatory }\end{array}$ & D irect \\
\hline Collateral-Source & Total D amages Payable In A M alpractice & \\
\hline R ule R eform & $\begin{array}{l}\text { Tort A re Statutorily R educed By A II Or } \\
\text { Part O f The D ollar V alue Of Collateral } \\
\text { Source Payments To The Plaintiff }\end{array}$ & D irect \\
\hline $\begin{array}{l}\text { Caps O n Contin- } \\
\text { gency Fees }\end{array}$ & $\begin{array}{l}\text { The Proportion Of A n A ward That A Plain- } \\
\text { tiff Can Contractually A gree To Pay A } \\
\text { Contingency-Fee A ttorney Is Capped A t A } \\
\text { Statutorily-Specified L evel }\end{array}$ & Indirect \\
\hline $\begin{array}{l}\text { M andatory Peri- } \\
\text { odic Payments }\end{array}$ & $\begin{array}{l}\text { Part Or A II Of D amages M ust Be D is- } \\
\text { bursed In The Form Of A n A nnuity That } \\
\text { Pays O ut O ver Time }\end{array}$ & Indirect \\
\hline J oint-A nd-Several & J oint A nd Several L iability Is A bolished & \\
\hline Liability R eform & $\begin{array}{l}\text { For N oneconomic O r T otal D amages, E i- } \\
\text { ther For A II Claims O r F or Claims In W hich } \\
\text { D efendants D id N ot A ct In Concert }\end{array}$ & Indirect \\
\hline Patient & D octors R eceive G overnment- & \\
\hline $\begin{array}{l}\text { Compensation } \\
\text { Fund }\end{array}$ & $\begin{array}{l}\text { A dministered Excess M alpractice Liability } \\
\text { Insurance, G enerally Financed Through A } \\
\text { Tax O n M alpractice Insurance Premiums }\end{array}$ & Indirect \\
\hline
\end{tabular}

O ur basic model therefore specifies each of the two measures of malpractice pressure as a function of state-fixed-effects, time-fixed-effects, specialty indicator variables, and liability reforms as follows:

$$
C_{i s t}=\theta_{t}+\alpha_{s}+X_{i s t} \beta+L_{s t} \phi_{m}+v_{i s t},
$$

where $\theta_{\mathrm{t}}$ is a time fixed-effect, $\alpha_{\mathrm{s}}$ is a state fixed-effect, $\beta$ is a vector of the corresponding average-effect estimates for specialty controls, $\phi_{\mathrm{m}}$ is the two- 
dimensional average effect of malpractice reforms on the growth in claims rates or malpractice insurance premiums, and $v_{\text {ist }}$ is a mean-zero independentlydistributed error term with $E\left(v_{\text {ist }} \mid X_{\text {ist, }} L_{\text {st. }}\right)=0$. B ecause the impact of law reforms on premiums is likely to be proportional, ${ }^{36}$ we estimate the impact of reforms on the natural logarithm of the physicians' annual malpractice premiums $\ln \left(M_{\text {ist }}\right)$ rather than on $M_{\text {ist. }}$ In addition, because insurance premiums in a state at a point in time depend on historical levels of malpractice pressure in the state, ${ }^{37}$ we allow the estimated time-fixed-effects $\theta_{t}$ to vary in reforming and nonreforming states in models of $\ln \left(\mathrm{M}_{\text {ist }}\right)$.

Because insurance premiums depend on historical levels of malpractice pressure, and because reforms generally affect only claims arising from injuries occurring after adoption, the full impact of reforms on insurance premiums and claim rates may not be immediate. For this reason, we also estimate the oneyear and three-year lagged impact of reforms. Specifically, we modify the basic model (1) by substituting $L_{s t}^{-1}$ and $L_{s t}{ }^{-3}$ for $L_{s t}$, where each element of $L_{s t}^{-1}=1$ if state s had adopted a reform (direct or indirect, as applicable) in year $t$ - 1 , and similarly, each element of $\mathrm{L}_{\mathrm{st}}^{-3}=1$ if state $\mathrm{s}$ had adopted a reform (again, direct or indirect, as applicable) in year $\mathrm{t}$ - 3 .

We also estimate two closely-related variants of the basic model (1). First, we estimate the impact of reforms on malpractice pressure by specialty, interacting the law reform indicator variables $L_{\text {st }}$ with an indicator variable $O B_{\text {ist }}=1$ if physician i was an obstetrician or gynecologist (OB/Gyn), to investigate whether liability reform has a greater impact on physician specialties traditionally thought to be high-malpractice-risk, as follows: ${ }^{38}$

$$
C_{i s t}=\theta_{t}+\alpha_{s}+X_{i s t} \beta+L_{s t} \phi_{m}+O B_{i s t} * L_{s t} \phi_{m}^{O B}+v_{i s t} .
$$

Second, using linear probability models, we estimate the impact of reforms on physician perceptions:

$$
P_{i s t}^{x}=\theta_{t}+\alpha_{s}+X_{i s t} \beta+L_{s t} \phi_{m}+v_{i s t} \text {. }
$$

We also estimate models of the impact of reforms that group direct and indirect reforms together. These models estimate the effect of a unidimensional liability indicator variable $L_{s t^{\prime}}$ where $L_{s t}=1$ if state $s$ at time t had adopted either a direct or an indirect reform, and zero otherwise. Model (2') is identical to model ( 1 ') except for this difference:

$$
P_{i s t}^{x}=\theta_{t}+\alpha_{s}+X_{i s t} \beta+L_{s t} \phi+v_{i s t} \text {, }
$$

36. See, e.g., Z uckerman et al., supra note 35. R esults were qualitatively similar for models substituting $M_{\text {ist }}$ for $\ln \left(M_{\text {ist }}\right)$.

37. SeeFrank A. SLoAn et A L., I NSUR IN M MdiCA L M A LPRA CTICE 146-62 (1991).

38. We follow Zuckerman et al., supra note 35 , at 170 , by examining OB/Gyn physicians separately as an example of a high-malpractice-risk specialty. 
whereas model ( $\left.2 a^{\prime}\right)$ identifies the unidimensional impact of reform on physician perception by specialty:

$$
P_{i s t}^{x}=\theta_{t}+\alpha_{s}+X_{i s t} \beta+L_{s t} \phi+O B_{i s t} * L_{s t} \phi^{O B}+v_{i s t} .
$$

Models ( $\left.3^{\prime}\right)$ and (4') estimate the joint effect of individual physicians' malpractice claims rates and unidimensional measures of law reforms on perceptions of malpractice-pressure-induced changes in treatment, to investigate the validity of physician surveys. Model ( $\left.3^{\prime}\right)$ uses the claims indicator variable $C_{\text {ist }}$ to measure malpractice claims rates, defining $\gamma$ as the effect of claims rates on perceptions:

$$
P_{i s t}^{x}=\theta_{t}+\alpha_{s}+X_{i s t} \beta+L_{s t} \phi+C_{i s t} \gamma+v_{i s t},
$$

whereas model ( $\left.4^{\prime}\right)$ uses in place of $C_{\text {ist }}$ an indicator variable $C E_{\text {ist' }}$ where $C E_{\text {ist }}=$ 1 if physician i ever had a malpractice claim filed against her, and zero otherwise. Model ( $3 a^{\prime}$ ) identifies the impact of claims rates and the unidimensional impact of reform on physician perception by whether a physician had a malpractice claim against her last year:

$$
P_{i s t}^{x}=\theta_{t}+\alpha_{s}+X_{i s t} \beta+L_{s t} \phi+C_{i s t} \gamma+C_{i s t} * L_{s t} \phi_{m}^{c}+v_{i s t}
$$

M odel (4a') is defined analogously to model (3a'), with $C E_{\text {ist }}$ substituted for $\mathrm{C}_{\text {ist }}$ to identify a similar impact based on whether a physician has ever had a malpractice claim against her.

B. Data

The data used in our analysis come from two principal sources. O ur data on liability reforms are taken directly from our previous research, ${ }^{39}$ updated to include adoption and repeal of reforms through 1993. Table 2 presents the chronology of legal reforms through 1993 that we analyze for each of the fifty states. The table shows that a number of states have implemented legal reforms at different times. For example, twenty-three states adopted direct reforms over the course of our 1984 to 1993 study period; twenty-four states adopted indirect reforms. Furthermore, a substantial number of states do not overlap in their adoption of policies; although thirty-three states adopted either direct or indirect reforms, only fourteen adopted both.

39. K essler \& M cClellan, supra note 12 , at $372-75$. 
TABLE 2

CHRONOLOGY OF LEGALREFORMSTHROUGH 1993*

\begin{tabular}{|c|c|c|c|c|c|}
\hline \multirow[b]{2}{*}{ State } & \multicolumn{2}{|c|}{ Y ear E ffective } & \multirow[b]{2}{*}{ State } & \multicolumn{2}{|c|}{$Y$ ear $E$ ffective } \\
\hline & $\begin{array}{l}\text { Direct } \\
\text { R eform } \\
\end{array}$ & $\begin{array}{l}\text { Indirect } \\
\text { R eform }\end{array}$ & & $\begin{array}{l}\text { Direct } \\
\text { R eform }\end{array}$ & $\begin{array}{l}\text { Indirect } \\
\text { Reform }\end{array}$ \\
\hline A labama & 1987 & 1987 & M ontana & 1987 & \\
\hline A laska & 1976, ‘86 & 1989 & Nebraska & 1960, '76 & 1976 \\
\hline A rizona & & 1988 & Nevada & & \\
\hline A rkansas & & & New H ampshire & $1986++$ & \\
\hline California & 1975 & 1975, '86 & New J ersey & 1987 & 1972, '76 \\
\hline Colorado & 1986 & 1986, ‘88 & New M exico & 1976 & 1976, ‘87 \\
\hline Connecticut & 1985 & 1986 & N ew Y ork & 1967, '84 & $1970, ' 85$ \\
\hline D elaware & & 1976 & North Carolina & & \\
\hline Florida & 1976, ‘86 & 1980, ‘85, ‘86 & N orth D akota & & 1987 \\
\hline Georgia & & & O hio & 1975 & 1988+++ \\
\hline H awaii & 1986 & & Oklahoma & & $1953, ' 78$ \\
\hline Idaho & 1987, '90 & 1987 & Oregon & 1975, '87 & $1975+, ' 87$ \\
\hline Illinois & 1976, ‘85 & 1985 & Pennsylvania & & 1975 \\
\hline Indiana & 1975 & 1975, ‘85 & R hode Island & 1976 & \\
\hline Iowa & 1975 & & South Carolina & & 1976 \\
\hline Kansas & 1986, ‘88 & $1974, ' 76$ & South D akota & 1976 & 1988 \\
\hline K entucky & & & Tennessee & 1975 & 1975 \\
\hline Louisiana & $1975, * *$ & 1975, '84 & Texas & 1977, '92 & \\
\hline M aine & 1989 & 1985 & U tah & 1985, '86 & 1985, ‘86 \\
\hline M aryland & 1986 & & V ermont & & 1970 \\
\hline M assachusetts & $1986, * *$ & 1986 & V irginia & 1974 & \\
\hline M ichigan & 1986 & 1981 & Washington & $* *$ & 1986 \\
\hline M innesota & 1986 & & W est V irginia & 1986 & \\
\hline M ississippi & & & Wisconsin & 1986++ & 1975, ‘86 \\
\hline M issouri & 1986 & 1986 & Wyoming & & $1986,{ }^{\prime} 87$ \\
\hline
\end{tabular}

* Except prejudgment interest. Montana imposed prejudgment interest in 1985. No other states repealed or imposed prejudgment interest in the years 1985-1993. The following states imposed mandatory prejudgment interest effective before 1984: A rkansas, Colorado, Iowa, Louisiana, M aine, M assachusetts, New H ampshire, N ew J ersey, North Carolina, O klahoma, Rhode I sland, U tah, and W est V irginia. Source: K essler \& M cClellan, supra note 12, tbl. II B (updated through 1993 with authors' research).

** Common law effective before 1984 prohibits punitive damages.

$+\quad$ Repealed 1987.

++ Held unconstitutional or expired, 1991.

+++ Held unconstitutional, 1993.

Our data on individual physicians are from the AMA SMS survey, a na- 
tionally-representative annual survey of approximately 4,000 physicians. ${ }^{40}$ Table 3 presents descriptive statistics on the AMA SMS variables used in analysis. ${ }^{41}$ A II of the SM S surveys except the 1984 supplemental "perceptions" survey were conducted in the year following the activities and experiences about which the survey inquired. ${ }^{42}$ F or consistency, we categorize all survey responses based on the year in which the relevant activities or experiences occurred, not the year in which the question was asked. Because no information on physicians' 1984 malpractice claims histories was collected by the core survey, the base year for analysis of the full sample is 1985.

For the full sample, Table 3 presents means weighted with the A M A SM S sampling weights; unweighted means are virtually identical. The leftmost three columns of Table 3 provide data for the nine cross-sections of survey responses from the 1985 through 1993 surveys. We use this data in models (1) and (1a) to estimate the impact of reforms on malpractice pressure. The first nonblank row of these columns shows that a significant fraction of physicians have malpractice claims filed against them in a given year-approximately eight percent-and that this number has been declining slightly over the 1985 to 1993 period. ${ }^{43}$ The next row of the table shows that between thirty-six and forty percent of physicians in our sample have ever had a malpractice claim filed against them, and that the share of physicians who have ever had a claim filed against them has risen over time. R eal malpractice insurance premiums have also risen over time, from an average of \$10,504 in 1985 to an average of \$11,101 in 1993 (both expressed in 1985 dollars), a real increase of approximately 5.7 percent.

40. See Center for Health Policy Research, supra note 23, app. A at 163.

41. Sample sizes in the table are less than 4,000 because some observations had missing data for one or more variables used in analysis. See id.

42. Seeid.

43. O ur calculated shares of physicians with claims is identical to those reported in Martin L. Gonzalez, Medical Professional Liability Claims and Premiums, 1985-1993, in CENTER FOR HEALTH Policy ResearCh, A MA, SOCIOECONOMIC Chara CTERISTICS Of MEDICAL PRACTICE 31, 33 tbl. 2 (1995). 
TABLE 3

MEANS (STANDARD DEVIATIONS) OF VARIABLES

USED IN ANALYSIS, A MA, SMS

\begin{tabular}{|c|c|c|c|c|c|}
\hline \multirow[b]{2}{*}{ Variable } & \multicolumn{2}{|c|}{ Full Sample } & \multirow[b]{2}{*}{$85-93$ avg } & \multicolumn{2}{|c|}{$\begin{array}{l}\text { Perceptions } \\
\text { Survey Sample }\end{array}$} \\
\hline & 1985 & 1993 & & 1984 & 1992 \\
\hline $\begin{array}{l}\text { M alpractice-Pressure-Induced (M- } \\
\text { P-I) R ecord K eeping ( } 1=\text { yes) }\end{array}$ & & & & 0.3083 & 0.6501 \\
\hline M-P-I D iagnostic Tests & & & & 0.2004 & 0.7310 \\
\hline M -P-I R eferrals For Consultation & & & & 0.1690 & 0.6284 \\
\hline M-P-I Time With Patients & & & & 0.1699 & 0.6734 \\
\hline Claims This Y ear ( $1=$ yes) & 0.0857 & 0.0783 & 0.0717 & 0.0819 & 0.0858 \\
\hline E ver $\mathrm{H}$ ad Claims ( 1 = yes) & 0.3606 & 0.3954 & 0.3773 & 0.3667 & 0.4372 \\
\hline Self-E mployed ( $1=$ yes) & 0.4218 & 0.2989 & 0.3591 & & \\
\hline $\begin{array}{l}\text { A nnual M alpractice Insurance } \\
\text { Premiums }\end{array}$ & $\begin{array}{l}\$ 10,504 \\
(11,229)\end{array}$ & $\begin{array}{l}\$ 11,101 \\
(18,947)\end{array}$ & $\begin{array}{l}\$ 11,496 \\
(15,371)\end{array}$ & & \\
\hline Specialty & & & & & \\
\hline $\begin{array}{l}\text { G eneral/F amily Practice } \\
\text { Internal M edicine }\end{array}$ & $\begin{array}{l}0.1611 \\
0.1935\end{array}$ & $\begin{array}{l}0.1331 \\
0.2349\end{array}$ & $\begin{array}{l}0.1478 \\
0.2182\end{array}$ & $\begin{array}{l}0.1681 \\
0.1490\end{array}$ & $\begin{array}{l}0.1232 \\
0.1854\end{array}$ \\
\hline G eneral Surgery & 0.0646 & 0.0546 & 0.0595 & 0.0627 & 0.0603 \\
\hline Otolaryngology & 0.0233 & 0.0174 & 0.0197 & 0.0209 & 0.0233 \\
\hline O rthopedic Surgery & 0.0327 & 0.0413 & 0.0376 & 0.0305 & 0.0454 \\
\hline Ophthalmology & 0.0373 & 0.0386 & 0.0396 & 0.0383 & 0.0431 \\
\hline U rological Surgery & 0.0220 & 0.0172 & 0.0206 & 0.0166 & 0.0198 \\
\hline Other Surgery & 0.0259 & 0.0235 & 0.0250 & 0.0235 & 0.0286 \\
\hline Pediatrics & 0.0705 & 0.0773 & 0.0729 & 0.0801 & 0.0790 \\
\hline O bstetrics/G ynecology & 0.0656 & 0.0652 & 0.0666 & 0.0810 & 0.0729 \\
\hline Psychology & 0.0723 & 0.0683 & 0.0691 & 0.0889 & 0.0675 \\
\hline R adiology & 0.0549 & 0.0537 & 0.0551 & 0.0784 & 0.0710 \\
\hline A nesthesiology & 0.0488 & 0.0569 & 0.0530 & 0.0514 & 0.0576 \\
\hline Pathology & 0.0254 & 0.0248 & 0.0245 & 0.0288 & 0.0347 \\
\hline O ther Specialties & 0.1020 & 0.0934 & 0.0907 & 0.0819 & 0.0881 \\
\hline $\mathrm{N}$ & 3,847 & 3,941 & 34,870 & 1,148 & 2,621 \\
\hline
\end{tabular}

N ote: M eans for full sample weighted using A M A SM S sampling weights. M alpractice insurance premiums are reported in 1985 dollars for physicians with nonzero responses (1985: $\mathrm{N}=2,764 ; 1993: \mathrm{N}$ $=2,873 ; 85-93: \mathrm{N}=29,871)$. O pinion survey questions in 1992 differ from questions in 1984. See supra text accompanying notes $45-46$. 
The rightmost two columns of Table 3 summarize the 1984 supplemental and 1992 survey samples that contain physicians' valid responses to questions about their perceptions of malpractice pressure's impact. Specifically, the questions related to four dimensions of the physicians' practices: recordkeeping, use of diagnostic tests, referrals for consultation, and time spent with patients. We characterize reported perceptions with the four indicator variables $P_{\text {ist }}{ }^{x}$ described previously, ${ }^{44}$ which describe whether the physician reported changing any of the four practice dimensions in response to malpractice pressure.

Unfortunately, these behavioral questions were not asked in exactly the same way in the 1984 and 1992 surveys. In the 1984 surveys, physicians were asked, "D uring the last 12 months, have you increased the number/amount of $X$ in response to the growth in malpractice claims, or not?," where $X$ represents one of the four dimensions of practice. ${ }^{45}$ In the 1992 survey, physicians were asked, "W hat percentage of X done in 1992 were due to concerns about malpractice?" ${ }^{46}$ R espondents who gave any nonzero answer were coded as altering treatment behavior in response to malpractice concerns. Thus, the higher rates of malpractice-sensitive behavior reported in 1992 are at least partly the result of the modified question format from incremental changes in malpractice pressure and behavior to levels of malpractice pressure and behavior.

$\mathrm{H}$ owever, because our analysis relies on the differences between geographic areas in trends in physicians' responses, the format change will not lead to bias in our results as long as the effect of the change in the questions' terms on physicians is uncorrelated with individual physicians' personal characteristics and uncorrelated with geographic area. Put another way, because our analysis examines changes over time in survey responses of physicians from states adopting reforms relative to changes over time in responses of physicians from nonadopting states, the effects of modifying a question that affects physicians equally in expectation have no net impact on the results.

A substantial share of physicians reported that malpractice pressure has affected their practice in multiple dimensions. ${ }^{47}$ For example, in 1984, approximately seventeen percent of physicians reported that they had increased referrals for consultation and time spent with patients in response to malpractice pressure; twenty percent reported increased malpractice-pressure-induced diagnostic tests; and almost one-third reported increased malpractice-pressureinduced record keeping. ${ }^{48}$ When asked about the impact of malpractice pressure in terms of its impact on the levels of treatment decisions in their practices, physicians responded even more strongly. Fully seventy-three percent of physicians, for example, reported that they had ordered diagnostic tests in re-

\footnotetext{
44. See supra text following note 33 .

45. A M A SM S, 1984 SU PPLEMENTAL SURVEY CODEBOOK.

46. See supra text accompanying note 24 .

47. See supra tbl. 3. R ows 1-4 of Table 3 show the percentage of physicians positively reporting malpractice-induced behavior. Id.

48. See id.
} 
sponse to malpractice pressure in $1992 .^{49}$

\section{IV}

\section{EMPIRICA L RESULTS}

Table 4 presents our estimates of the impact of reforms on malpractice pressure for our basic models (1) and (1a). The top panel of Table 4, presenting model (1) results, shows that liability reforms reduce malpractice pressure, although they do not do so immediately. Indeed, the leftmost two columns of the table show that the immediate estimated impact of liability reforms on claims rates $C_{\text {ist }}$ and the natural log of malpractice insurance premiums $\ln \left(\mathrm{M}_{\text {ist }}\right)$ is not statistically significantly negative, and in some cases is actually positive. H owever, within one year after the passage of direct reforms, the trend in malpractice claims rates in reform states is substantially smaller than the trend in nonreform states, by 2.07 percentage points; this difference is statistically significant at the five percent level. Indirect reforms, such as caps on contingency fees and mandatory periodic payments provisions, do not have a statistically significant effect on claiming behavior, and the impact of one-year lagged indirect reforms on insurance premiums is also insignificant. W ithin three years after adoption, however, physicians from states adopting direct reforms show substantially and statistically significant lower trend growth in their real malpractice insurance premiums of approximately 8.4 percent. Indirect reforms do not have a significant impact on either outcome three years after adoption.

49. Seeid. 
TABLE 4

EFFECTS OF DIRECT AND INDIRECT LIABILITY REFORMS ON M A LPRA CTICE PRESSURE, A MA SMS, 1985-1993

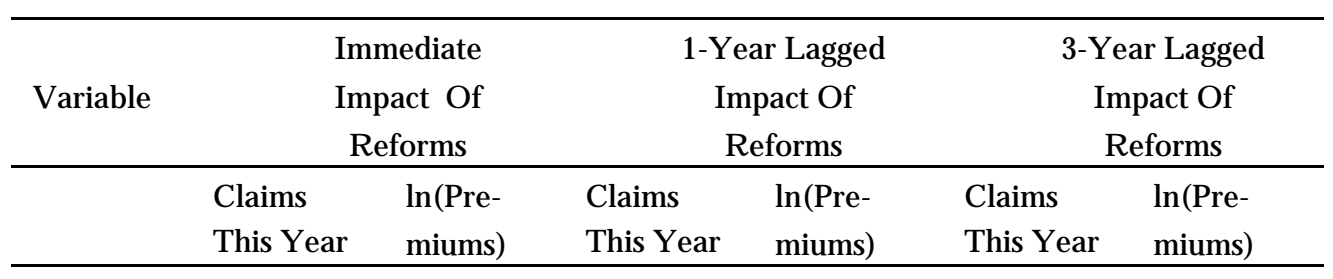

M odel 1: Effect Of R eforms, Controlling For Specialty A nd State- A nd Time-Fixed E ffects

\begin{tabular}{lllllll}
\hline Direct & -0.0029 & $0.0752^{* *}$ & $-0.0207^{* *}$ & $0.0815^{* *}$ & $-0.0208^{* *}$ & $-0.0843^{* *}$ \\
R eforms & $(0.0068)$ & $(0.0272)$ & $(0.0060)$ & $(0.0303)$ & $(0.0055)$ & $(0.0336)$ \\
Indirect & 0.0093 & $-0.0497^{*}$ & -0.0052 & -0.0117 & -0.0008 & -0.0405 \\
R eforms & $(0.0073)$ & $(0.0291)$ & $(0.0061)$ & $(0.0286)$ & $(0.0053)$ & $(0.0297)$ \\
\hline
\end{tabular}

Model 1a: E ffect Of R eforms By Specialty, Controlling For Specialty A nd State- And Time-Fixed E ffects

\begin{tabular}{lllllll}
\hline Direct & -0.0014 & $0.0764^{* *}$ & $-0.0194^{* *}$ & $0.0820^{* *}$ & $-0.0206^{* *}$ & $-0.0864^{* *}$ \\
R eforms & $(0.0068)$ & $(0.0274)$ & $(0.0061)$ & $(0.0304)$ & $(0.0056)$ & $(0.0337)$ \\
Indirect & 0.0090 & $-0.0549^{*}$ & -0.0053 & -0.0143 & -0.0004 & -0.0446 \\
R eforms & $(0.0073)$ & $(0.0241)$ & $(0.0061)$ & $(0.0287)$ & $(0.0054)$ & $(0.0298)$ \\
OB /G yn & $0.0655^{* *}$ & $1.2624^{* *}$ & $0.0642^{* *}$ & $1.2723^{* *}$ & $0.0618^{* *}$ & $1.2596^{* *}$ \\
& $(0.0093)$ & $(0.0251)$ & $(0.0088)$ & $(0.0249)$ & $(0.0081)$ & $(0.0231)$ \\
Direct & $-0.0233^{* *}$ & -0.0217 & -0.0193 & -0.0098 & -0.0044 & 0.0317 \\
R eforms* & $(0.0117)$ & $(0.0354)$ & $(0.0123)$ & $(0.0356)$ & $(0.0142)$ & $(0.0414)$ \\
OB /G yn & & & & & & \\
Indirect & 0.0016 & $0.0728^{* *}$ & 0.0002 & 0.0376 & -0.0058 & 0.0543 \\
R eforms* & $(0.0111)$ & $(0.0317)$ & $(0.0113)$ & $(0.0322)$ & $(0.0133)$ & $(0.0388)$ \\
OB /G yn & & & & & & \\
N & 34,870 & 25,303 & 34,870 & 25,303 & 34,870 & 25,303 \\
\hline
\end{tabular}

N ote: Standard errors in parentheses. O bservations weighted using AM A SM S sampling weights. $B$ oth models include 14 categorical variables to control for specialty. M alpractice insurance premiums measured in constant 1985 dollars. Models of the effect of reforms on insurance premiums allow the estimated time-fixed-effects to vary in reforming and nonreforming states.

* Statistically significant at the .10 level.

** Statistically significant at the .05 level.

The estimated effects of direct reforms represent a substantial change in the incentives facing physicians. ${ }^{50}$ The two percentage point decline in claims rates

50. Our estimated effects of direct reforms are larger than, but not inconsistent with, findings from 
in reform relative to nonreform states translates approximately into a twentyfour percent decline (2.08/8.57) relative to the 1985 baseline average claims rate. Similarly, whereas physicians from nonreforming states experienced real malpractice insurance premium increases over the 1985 to 1993 period, physicians from reforming states experienced slight declines.

The estimated time path of the impact of direct reforms shown in the top panel of Table 4-specifically that the reforms affect claims rates within one year and insurance premiums within three years-is consistent with other research on the operation of the malpractice liability system. In general, reforms apply to injuries occurring after their adoption. However, a substantial amount of time elapses between the occurrence of an alleged injury, the filing of a malpractice claim, the payment of compensation (or the reserving of funds to pay compensation), and the setting of malpractice insurance rates. For example, approximately a year-and-a-half on average elapses between the occurrence of an alleged injury and the notification of a physician's malpractice insurer; depending on the sample and the state, approximately four years elapse on average between injury and claim closure. ${ }^{51}$ Thus, a reform adopted in year $t$ could begin to affect claims rates only in year $t+1$, and would be expected to affect insurance premiums only some years after that. The absence of substantial long-term effects of indirect reforms is consistent with our previous research. ${ }^{52}$

The bottom panel of Table 4 provides estimates of the impact of reforms by specialty from model (1a). The bottom panel confirms that specialties that are conventionally labeled high-malpractice risk, such as $O B / G$ yn, are subject to much higher levels of malpractice pressure. Comparing the fifth row of Table 4 to the sample averages in Table 3 shows that O B / G yn specialists incur malpractice claims at approximately twice the rate of all physicians on average. ${ }^{53} \mathrm{How}$ ever, there is no evidence that reforms affect high-risk specialists differently than they affect physicians generally; coefficients on reform/specialty interaction terms are not statistically significant.

Table 5 begins our analysis of how changes in malpractice pressure influence physician attitudes, based on the merged 1984 and 1992 surveys and models ( $\left.1^{\prime}\right)$ through (4'). A Ithough direct and indirect reforms do not have statistically significant independent impacts on physicians' perceptions of the impact

earlier studies. For example, in Patricia Danzon, The Frequency and Severity of M alpractice Claims: New Evidence, 49 LAW \& CONTEMP. PROBS. 57, 72 (Spring 1986), the author finds that collateral source rule reforms reduce claims frequency by $14 \%$. O ur standard errors would lead us to accept her findings. In addition, our estimated effects of direct reforms are larger than that found in Zuckerman et al., supra note 35, at 175-79. The differences in findings between our study and their study may be due to the fact that we used data from more recent time periods and used a more flexible modeling structure, allowing reforms to affect claims rates only with some time lag. Indeed, in models in which we constrain the reforms to affect claims rates immediately, see Zuckerman et al., supra note 35, at 174 (using same methods), we also estimate the effects of reforms on claims rates to be small and statistically insignificant.

51. See, e.g., K essler \& M cClellan, supra note 19; SL OA N ET A L., supra note 4, at 26 tbl. 2.4.

52. See, e.g., K essler \& M cClellan, supra note 12 , at 382.

53. This is consistent with $\mathrm{G}$ onzalez, supra note 43 , at 32 tbl. 1, 33 tbl. 2. 
of malpractice pressure (model $\left(1^{\prime}\right)$ ), reforms do have a significant impact when they are grouped together into a unidimensional law reform indicator variable $L_{\text {st }}$ (models $\left.\left(2^{\prime}\right)-\left(4^{\prime}\right)\right)$, where $L_{s t}=1$ if state $s$ at time t had adopted either a direct or an indirect reform, and $\mathrm{L}_{\text {st }}=0$ otherwise. R esults from the second panel of the table show that, relative to their counterparts from nonadopting states, physicians from states adopting reforms report lower growth in malpracticeinduced treatment over the 1984 to 1992 period; the differences in trends in rates of referrals for consultation and in time spent with patients are statistically significant at the five percent level.

A Ithough these results do not by themselves show that reforms reduce the prevalence of defensive practices, they do suggest that physician surveys can be a valid measure of actual behavior. If the baseline levels of referrals and time spent per patient were above the socially optimal levels, then reforms would reduce the prevalence of defensive medicine. However, if the baseline levels of referrals and time spent on patients were at or below the socially optimal levels, then reforms would result in socially inadequate care. Put another way, without information on patient satisfaction or health outcomes, these results do not have any efficiency or social welfare implications. However, these results do show that physician perceptions are consistent with objective measures of the levels of malpractice pressure created by the liability system, as measured by the results in Table 4 and in our previous research.

The bottom panels of Table 5 report data on the validity of survey data on physician perceptions in more detail. Specifically, models ( $\left.3^{\prime}\right)$ and (4') estimate the joint impact of liability reforms and individuals' malpractice claims histories. O ur results clearly suggest that physician surveys may also capture negative feelings about the malpractice system and/or unobserved differences across physicians, as well as exogenous differences in malpractice pressure due to differences in laws. In both models ( $\left.3^{\prime}\right)$ and $\left(4^{\prime}\right)$, individual claims history is strongly correlated with the likelihood of reporting a malpractice-pressureinduced change in each of the four dimensions of practice patterns, even after holding constant the status of state law reforms. This hypothesis is strengthened by the fact that more recent claims history has a greater influence on physician perceptions. The impact of a claim last year on perceived changes in practice patterns is between 1.4 and 2.3 times as great as the impact of a claim at any point in a physician's career, depending on the dimension of practice under consideration. E ven after controlling for individual physicians' claims histories, law reforms still have a statistically significant impact on physician perceptions of the malpractice system. 


\section{TABLE 5}

EFFECTS OF LIABILITY REFORMSAND CLAIMS HISTORY ON PHYSICIAN PERCEPTIONS OF M A LPRA CTICE-PRESSURE-INDUCED ChANGESIN PRACTICE PATTERNS, A MA SMS, 1984 AND 1992

\begin{tabular}{|c|c|c|c|c|}
\hline \multirow[b]{2}{*}{ V ariable } & \multicolumn{4}{|c|}{$\begin{array}{l}\text { 3-Y ear L agged E ffect Of R eforms O } n \text { Perceptions Of } \\
\text { M alpractice-Pressure-Induced.... }\end{array}$} \\
\hline & $\begin{array}{l}\text { Record } \\
\text { Keeping }\end{array}$ & $\begin{array}{l}\text { Diagnostic } \\
\text { Tests }\end{array}$ & $\begin{array}{l}\text { R eferrals F or } \\
\text { Consultation }\end{array}$ & $\begin{array}{l}\text { Time w/ } \\
\text { Patients }\end{array}$ \\
\hline \multicolumn{5}{|c|}{$\begin{array}{l}\text { M odel 1': E ffect Of R eforms, Controlling For Specialty And } \\
\text { State- A nd T Time-Fixed E ffects }\end{array}$} \\
\hline D irect $R$ eforms & $\begin{array}{l}-0.0171 \\
(0.0346)\end{array}$ & $\begin{array}{l}-0.0294 \\
(0.0310)\end{array}$ & $\begin{array}{c}-0.0425 \\
(0.0327)\end{array}$ & $\begin{array}{c}-0.0132 \\
(0.0322)\end{array}$ \\
\hline Indirect R eforms & $\begin{array}{l}-0.0337 \\
(0.0347)\end{array}$ & $\begin{array}{r}0.0150 \\
(0.0311)\end{array}$ & $\begin{array}{l}-0.0329 \\
(0.0328)\end{array}$ & $\begin{array}{r}-0.0399 \\
(0.0323)\end{array}$ \\
\hline \multicolumn{5}{|c|}{$\begin{array}{c}\text { Model 2': U nidimensional E ffect O f R eforms, Controlling For } \\
\text { Specialty A nd State- A nd T ime-F ixed E ffects }\end{array}$} \\
\hline $\begin{array}{l}\text { Direct O r Indirect } \\
\text { R eforms }\end{array}$ & $\begin{array}{l}-0.0407 \\
(0.0362)\end{array}$ & $\begin{array}{l}-0.0229 \\
(0.0324)\end{array}$ & $\begin{array}{c}-0.0822^{* *} \\
(0.0342)\end{array}$ & $\begin{array}{r}-0.0677^{* *} \\
(0.0337)\end{array}$ \\
\hline \multicolumn{5}{|c|}{$\begin{array}{c}\text { M odel 3': U nidimensional E ffect O f R eforms, Controlling For M alpractice } \\
\text { Claims L ast Y ear, Specialty, A nd State A nd Time-Fixed E ffects }\end{array}$} \\
\hline $\begin{array}{l}\text { D irect Or Indirect } \\
\text { R eforms }\end{array}$ & $\begin{array}{l}-0.0396 \\
(0.0361)\end{array}$ & $\begin{array}{l}-0.0220 \\
(0.0323)\end{array}$ & $\begin{array}{c}-0.0813^{* *} \\
(0.0342)\end{array}$ & $\begin{array}{r}-0.0667 * * \\
(0.0336)\end{array}$ \\
\hline $\begin{array}{l}\text { M alpractice Claims } \\
\text { This Y ear }\end{array}$ & $\begin{array}{l}0.1340 * * \\
(0.0279)\end{array}$ & $\begin{array}{l}0.1029 * * \\
(0.0250)\end{array}$ & $\begin{array}{l}0.0982^{* *} \\
(0.0264)\end{array}$ & $\begin{array}{l}0.1168^{* *} \\
(0.0260)\end{array}$ \\
\hline \multicolumn{5}{|c|}{$\begin{array}{l}\text { Model 4': U nidimensional E ffect Of R eforms, Controlling For Career } \\
\text { M alpractice Claims H istory, Specialty, A nd State- A nd Time-Fixed-E ffects }\end{array}$} \\
\hline $\begin{array}{l}\text { Direct Or Indirect } \\
\text { R eforms }\end{array}$ & $\begin{array}{l}-0.0379 \\
(0.0361)\end{array}$ & $\begin{array}{l}-0.0208 \\
(0.0323)\end{array}$ & $\begin{array}{c}-0.0809 * * \\
(0.0342)\end{array}$ & $\begin{array}{r}-0.0662^{* *} \\
(0.0333)\end{array}$ \\
\hline $\begin{array}{l}\text { Ever } \mathrm{H} \text { ad } \mathrm{M} \text { alpractice } \\
\text { Claims }\end{array}$ & $\begin{array}{l}0.0956 * * \\
(0.0164)\end{array}$ & $\begin{array}{l}0.0677^{* *} \\
(0.0147)\end{array}$ & $\begin{array}{l}0.0433^{* *} \\
(0.0155)\end{array}$ & $\begin{array}{l}0.0512^{* *} \\
(0.0153)\end{array}$ \\
\hline
\end{tabular}

N ote: Based on information from 1984 supplemental and 1992 survey. $N=3,769$. Standard errors in parentheses. All models include 14 categorical variables to control for specialty. 0 pinion survey questions in 1992 differ from questions in 1984. See supra text accompanying notes 45-46.

** Statistically significant at the .05 level.

Table 6 investigates whether the impact of reforms on reported malpractice-pressure-induced changes in practice patterns varies by specialty or by claims history. The top panel of the table presents estimates of the impact of reforms by specialty. Although $O B / G$ yn specialists experience significantly 
greater levels of malpractice pressure, ${ }^{54}$ they are not systematically more likely to report changing practice patterns for that reason, as shown by the results in the second row of Table 6. Furthermore, as shown in the third row, reforms do not have a systematic differential effect on $O B / G$ yn perceptions of the impact of malpractice pressure. This is consistent with estimates from model (1a) that show that reforms do not affect objective measures of malpractice pressure facing $O B / G$ yn specialists differently than they affect pressure facing physicians generally.

Estimates of the impact of reforms by claims history are consistent across specifications and provide some evidence on how reforms affect the perceptions of physicians with and without adverse claims histories. A mong those physicians who had a claim filed against them in the previous year, those in nonreform states report a statistically significant smaller increase in the rate of referrals for consultation when compared to those in reform states. R elative to physicians in nonreform states who had a claim filed against them last year, physicians in reform states who had a claim filed against them last year report a statistically significantly smaller increase in the rate of referrals for consultation (model (3a')); and physicians in reform states who ever had a malpractice claim filed against them report a statistically significantly smaller increase in recordkeeping, relative to physicians in nonreform states with a claims history (model $\left.\left(4 a^{\prime}\right)\right)$. These results suggest that actual experiences with the malpractice system have somewhat less dramatic consequences for physician attitudes in states with malpractice reforms. While it is not possible for us to model explicitly how one physician's experience of defending against a malpractice claim influences the perceptions of other physicians in the state who have not had an encounter with the liability system, these results do suggest that malpractice law reforms change medical practice patterns by changing the nature of the experience of being sued.

54. Seetbl.4 supra. 
TABLE 6

EFFECTSOF LIABILITY REFORMSAND CLA IMSHISTORY ON PHYSICIAN Perceptions of M A LPRA CTICE-INDU CEd Changesin Pra CTICE PA TTERns, A MA SMS, 1984 AND 1992

\begin{tabular}{|c|c|c|c|c|}
\hline \multirow[b]{2}{*}{ Variable } & \multicolumn{4}{|c|}{$\begin{array}{l}\text { 3-Y ear L agged E ffect Of R eforms On Perceptions Of } \\
\text { M alpractice-Pressure-Induced ... }\end{array}$} \\
\hline & $\begin{array}{l}\text { Record } \\
\text { K eeping }\end{array}$ & $\begin{array}{l}\text { Diagnostic } \\
\text { Tests }\end{array}$ & $\begin{array}{l}\text { Referrals For } \\
\text { Consultation }\end{array}$ & $\begin{array}{l}\text { Time w/ } \\
\text { Patients }\end{array}$ \\
\hline \multicolumn{5}{|c|}{$\begin{array}{l}\text { M odel 2a': U nidimensional E ffect O f R eforms By Specialty, Controlling For Specialty A nd } \\
\text { State- A nd T ime-Fixed-E ffects }\end{array}$} \\
\hline $\begin{array}{l}\text { D irect Or Indirect } \\
\text { R eforms }\end{array}$ & $\begin{array}{l}-0.0387 \\
(0.0365)\end{array}$ & $\begin{array}{l}-0.0211 \\
(0.0326)\end{array}$ & $\begin{array}{l}-0.0897 * * \\
(0.0345)\end{array}$ & $\begin{array}{l}-0.0648^{*} \\
(0.0339)\end{array}$ \\
\hline OB/G yn & $\begin{array}{l}0.0777^{*} \\
(0.0466)\end{array}$ & $\begin{array}{l}0.0000 \\
(0.0416)\end{array}$ & $\begin{array}{l}-0.1019 * * \\
(0.0440)\end{array}$ & $\begin{array}{l}0.0264 \\
(0.0433)\end{array}$ \\
\hline $\begin{array}{l}\text { D irect// ndirect } \\
\text { R eforms*OB } / G \text { yn }\end{array}$ & $\begin{array}{l}-0.0274 \\
(0.0584)\end{array}$ & $\begin{array}{l}-0.0238 \\
(0.0522)\end{array}$ & $\begin{array}{l}0.1043^{*} \\
(0.0551)\end{array}$ & $\begin{array}{l}-0.0404 \\
(0.0542)\end{array}$ \\
\hline \multicolumn{5}{|c|}{$\begin{array}{l}\text { M odel 3a': U nidimensional E ffect O f R eforms B y M alpractice Claims Status } L \text { ast } Y \text { ear, } \\
\text { Controlling F or M al practice Claims L ast } Y \text { ear, Specialty, A nd State- A nd T ime-F ixed-E ffects }\end{array}$} \\
\hline $\begin{array}{l}\text { D irect Or Indirect } \\
\text { R eforms }\end{array}$ & $\begin{array}{l}-0.0378 \\
(0.0365)\end{array}$ & $\begin{array}{l}-0.0255 \\
(0.0326)\end{array}$ & $\begin{array}{l}-0.0737^{* *} \\
(0.0345)\end{array}$ & $\begin{array}{l}-0.0644^{*} \\
(0.0339)\end{array}$ \\
\hline Claims $L$ ast $Y$ ear & $\begin{array}{l}0.1438^{* *} \\
(0.0387)\end{array}$ & $\begin{array}{l}0.0831^{* *} \\
(0.0346)\end{array}$ & $\begin{array}{l}0.1410^{* *} \\
(0.0365)\end{array}$ & $\begin{array}{l}0.1297^{* *} \\
(0.0360)\end{array}$ \\
\hline $\begin{array}{l}\text { D irect/I ndirect R e- } \\
\text { form* Claims L ast } \\
\text { Y ear }\end{array}$ & $\begin{array}{l}-0.0204 \\
(0.0553)\end{array}$ & $\begin{array}{l}0.0409 \\
(0.0495)\end{array}$ & $\begin{array}{l}-0.0885 * \\
(0.0523)\end{array}$ & $\begin{array}{l}0.0266 \\
(0.0514)\end{array}$ \\
\hline \multicolumn{5}{|c|}{$\begin{array}{l}\text { M odel 4a': U nidimensional E ffect O f R eforms B y Career M alpractice Claims H istory, } \\
\text { Controlling For Career M alpractice Claims H istory, Specialty, State- A nd Time-F ixed-E ffects }\end{array}$} \\
\hline $\begin{array}{l}\text { D irect Or Indirect } \\
\text { R eforms }\end{array}$ & $\begin{array}{l}-0.0056 \\
(0.0387)\end{array}$ & $\begin{array}{l}-0.0194 \\
(0.0347)\end{array}$ & $\begin{array}{l}-0.0621^{*} \\
(0.0342)\end{array}$ & $\begin{array}{l}-0.0554 \\
(0.0361)\end{array}$ \\
\hline E ver $\mathrm{H}$ ad Claims & $\begin{array}{l}0.1307 * * \\
(0.0224)\end{array}$ & $\begin{array}{l}0.0693^{* *} \\
(0.0200)\end{array}$ & $\begin{array}{l}0.0638 * * \\
(0.0264)\end{array}$ & $\begin{array}{l}0.0630 * * \\
(0.0209)\end{array}$ \\
\hline $\begin{array}{l}\text { D irect/Indirect R e- } \\
\text { forms* } \mathrm{H} \text { ad Claims }\end{array}$ & $\begin{array}{l}-0.0720^{* *} \\
(0.0312)\end{array}$ & $\begin{array}{l}-0.0033 \\
(0.0280)\end{array}$ & $\begin{array}{l}-0.0420 \\
(0.0296)\end{array}$ & $\begin{array}{l}-0.0242 \\
(0.0292)\end{array}$ \\
\hline
\end{tabular}

Note: Based on information from the 1984 supplemental and 1993 survey. $N=3,769$. Standard errors are in parentheses. All models include 14 categorical variables to control for specialty. O pinion survey questions in 1992 differ from questions in 1984. See supra text accompanying notes 45-46.

* Statistically significant at the .10 level.

** Statistically significant at the .05 level. 


\section{V \\ CONCLUSION}

Understanding how and why liability laws and liability reforms alter the medical treatment decisionmaking process is central to reforming the current malpractice liability system in this country which neither provides incentives for physicians to take optimal precautions against patient injury, ${ }^{55}$ nor reliably provides compensation to injured patients. ${ }^{56}$ Survey methods serve a valuable role in this process because they measure how malpractice pressure affects physician perceptions of appropriate practices, and they thereby capture an important determinant of treatment decisions. However, much of the previous research using survey data in this area has several well-studied drawbacks: Survey methods are prone to response bias, and survey research has not provided policy-relevant evidence on the impact of specific legal reforms on physician perceptions of the impact of malpractice pressure on practice patterns.

We present four findings. First, in states that have enacted liability reforms that directly reduce malpractice pressure, physicians face lower growth over time in malpractice claims rates and in real malpractice insurance premiums. Second, physicians from reforming states report significant relative declines in the perceived impact of malpractice pressure on practice patterns. Third, individual physicians' personal experiences with the malpractice system are a key determinant of the perceived importance of defensive medicine-physicians who have had a malpractice claim filed against them, particularly a recent claim, are more likely to report changes in practices as a result of malpractice pressure than physicians who have not. Fourth, the impact of individual physicians' claims experience on perceptions is smaller in reforming than in nonreforming states. Taken together, these results suggest that law reforms affect physicians' attitudes, both by reducing the probability of an encounter with the liability system, and by changing the nature of the experience of being sued for those physicians who defend against malpractice claims.

These results validate our previous research by illustrating how reforms change physician incentives. Our 1996 study showed that reforms changed physician behavior, but it stopped short of investigating the mechanism by which reforms altered medical practices. ${ }^{57}$ O ur current results, however, indicate that mechanisms commonly cited by physicians in anecdotal reportsnamely the frequency and severity of malpractice claims-may play an important role in fostering defensive medical practices. R eforms appear to affect practices particularly through their impact on the attitudes of physicians who experience lawsuits. In this paper, we did not explicitly model why attitudes of physicians who are sued in states with reforms are less dramatically affected

55. See, e.g., Kessler \& McClellan, supra note 12, at 388; K essler \& McClellan, supra note 19; K essler \& M cClellan, supra note 10.

56. See WeILER ET AL., supra note 5, at 139-40; HARVARd MEdICAL PRACTICE Study, supra note 5 , exec. summary at 6 .

57. See K essler \& M cClellan, supra note 12 , at 388. 
than attitudes of physicians in states without reforms. ${ }^{58}$ However, the differences we find here suggest that malpractice claims are less onerous in states with reforms, providing a foundation for their differential impact on physician attitudes.

In addition, our results suggest that physician surveys do relate to actual behavior. The fact that state-level reforms reduce both measures of malpractice pressure and physician perceptions of the impact of malpractice pressure suggests that survey methods provide valid measures of defensive practices. $\mathrm{N}$ onetheless, further investigation of the extent to which survey methods are valid will be a fruitful topic of further research. B ecause the format of the survey questions regarding the impact of malpractice pressure on practice patterns changed over time ${ }^{59}$ we needed to assume that the impact of the change in the questions' terms was uncorrelated with physicians' personal characteristics and uncorrelated with geographic area in order to identify the impact of law reforms on relative changes in the rates of reported malpractice-pressure-induced changes in behavior. Future research might investigate the validity of our assumption, or might seek to replicate our results with comparable survey questions. In addition, our results suggest that physician surveys do, in part, measure negative feelings about the malpractice system, or unobserved differences across physicians, rather than the targeted issue of the impact of malpractice pressure on perceptions and practice patterns. M alpractice claims history has a strong positive correlation with perceived changes in malpractice-pressureinduced changes in practices, and more recent history is more strongly correlated with perceived changes than is less recent history. Future research might investigate the extent to which these findings represent actual changes in practices, rather than the well-studied problem of response bias.

58. Investigation of this question is in K essler \& M cClellan, supra note 19.

59. The 1984 survey asked the question in terms of the impact of changes in pressure on changes in behavior; the 1992 survey asked the question in terms of the impact of levels of pressure on levels of behavior. 